\title{
Far from the Madding Crowd: the Molecular Basis for Immunological Escape of Plasmodium falciparum
}

\author{
Manuel E. Patarroyo ${ }^{1,2, *}$, Jorge Aza-Conde ${ }^{1}$, \\ Armando Moreno-Vranich1, Laura Pabón ${ }^{1}$, \\ Yahson Varela ${ }^{1}$ and Manuel A. Patarroyo ${ }^{1,3}$ \\ ${ }^{1}$ Fundación Instituto de Inmunología de \\ Colombia (FIDIC), Bogotá, Colombia \\ 2Universidad Nacional de Colombia, Bogotá, \\ Colombia \\ 3Universidad del Rosario, Bogotá. Colombia \\ ${ }^{*}$ Correspondence: mepatarr@gmail.com
}

DOI: https://doi.org/10.21775/cimb.022.065

\begin{abstract}
Like Thomas Hardy's famous novel Far from the Madding Crowd, Plasmodium falciparum parasites display their most relevant survival structures (proteins) involved in host cell invasion far away from the immune system's susceptible regions, displaying tremendous genetic variability, to attract the immune response and escape immune pressure. The 3D structure localisation of the conserved amino acid sequences of this deadly parasite's most relevant proteins involved in host cell invasion, as well as the location of the highly polymorphic, highly immunogenic regions, clearly demonstrates that such structures are far apart, sometimes $90^{\circ}$ to $180^{\circ}$ opposite, thereby rendering the immune response useless. It is also shown here that these conserved, functionally-relevant structures are immunologically silent, since no immune response has been induced.
\end{abstract}

\section{Introduction}

It should be pointed out from the start that this manuscript only deals with the functional and immunological activities of molecules whose 3D structures have already been determined (i.e. published to date); it also covers the structural biology and corresponding genetic polymorphism with some protein-bound, monoclonal antibody 3D structures to illustrate their very distant and sometimes opposite location in the molecule, far away from their functionally relevant sequences.

\section{Escape mechanism}

Malaria is caused by an infected female Anopheles mosquito's bite injecting sporozoites (Spz) (larva-like parasites in a mosquito's salivary glands) into a human host which travel through the bloodstream to the liver, where they recognise and invade the host's liver cells or hepatocytes, giving rise to $\sim 30,000$ merozoites (Mrz) (pear-shaped parasite) per infected hepatocyte. Mrz are released into the bloodstream to specifically invade and infect erythrocytes or red blood cells (RBCs), thus marking the beginning of the intra-erythrocyte asexual development stage. 48 hours later $32-40$ Mrz are released from infected RBCs (iRBC) for subsequent invasion and infection of new RBC (Weiss et al., 2015). Some Mrz differentiate into male and female gametes (banana-shaped) to be taken up by a mosquito during its blood meal, where they develop into new Spz, to start a new infection cycle (Patarroyo and Patarroyo, 2008; Curtidor et al., 2011).

Parasites change their morphology during these reproductive cycles, cell targets and molecules so that Spz can bind to small vessels in endothelial cells to traverse the vascular wall, to Kupffer cells to activate invasion-mediating molecules, to hepatocytes to invade them and reproduce themselves and to RBC during erythrocyte stage to proliferate. The latter gives rise to new Mrz and the critical manifestations of malaria. Male and female gametes bind to a mosquito's midgut lamina propria cells to reproduce in an invertebrate host and new Spz bind to a mosquito's salivary glands to rest and prepare molecules for the next invasive stage in a vertebrate host. All of the above cells have different receptor molecules and characteristics (Patarroyo and Patarroyo, 2008; Curtidor et al., 2011). 
Multiple mechanisms have been developed by microbes to escape immune pressure; these would include diverse developmental stages where highly-evolved microbes, such as the Plasmodium falciparum parasite, the causative agent of the most aggressive form of malaria, causing $\sim 214$ million new cases and $\sim 438,000$ deaths annually (WHO, 2015), changes its morphology, molecule functions and target cells (named stages) in very short periods of time, faster than the immune response, to escape immunological pressure.

Taking Thomas Hardy's famous novel Far from the Madding Crowd (Hardy, 1874) as an analogy, Plasmodium falciparum parasites display their most relevant survival structures (proteins) involved in host cell invasion, or their Achilles' heel (Patarroyo et al., 2016a), far away from the immune system's susceptible regions. Once the parasite is inside a host's cells it is largely protected from attack by the immune response. During invasion $P$. falciparum parasite molecules can hide or cover functionally relevant structures or domains with some other domains or structures to expose them only during the last moments of invasion to perform their fundamental functions (Patarroyo et al., 2016a; Patarroyo et al., 2016b).

Over the last 30 years our group has identified conserved amino acid (aa) sequences having high specific host cell binding capacity (to RBC, hepatocytes or endothelial cells); such sequences, called conserved high activity binding peptides (cHABPs), are directly involved in invading or using such cells. However, these cHABPs have been shown to be immunologically silent, i.e. they are not immunogenic nor do they induce protection. (Patarroyo et al., 2010; Patarroyo et al., 2012)

The following part of this manuscript only deals with Spz molecules involved in invasion of hepatocytes whose 3D structures have already been determined. The relevant structures include circumsporozoite protein 1 (CSP-1) cHABP 4397 ( ${ }^{331}$ IQNSLSTEWSPCSVTCGNGI ${ }^{350}$ ) (Figure 1A, dark yellow) forming a hydrophobic groove or cavity ( $\left.600 \AA^{3}\right)$ where hepatocyte heparan sulphate proteoglycan (HSPG) binds (Doud et al., 2012). Spz also use the thrombospondin-related associated protein (TRAP) von Willebrand factor A-like domain (vWA) containing the metal-ion-dependent adhesion site (MIDAS) which binds $\mathrm{Mg}^{2+}$ where CHABP 3271 ( ${ }^{161}$ TDGIPDSYQDSLKES ${ }^{175}$ ) has been located (Figure 1B, dark yellow with two $\mathrm{Mg}^{2+}$ ions in black). MIDAS is needed to start this protein's attachment to endothelial cells and mediate Spz motility. cHABP 3279 (201FLVGCHPSDGKCNLY ${ }^{215}$ ) (Figure 1B, green) forms part of a cavity where a still-unrecognised receptor binds to allow TRAP dimerisation and surface attachment (Pihlajamaa et al., 2013). In the same multifunctional TRAP molecule, the thrombospondin-related (TSR) domain contains cHABPs 3287 (241TASCGVWDEWSPYSV ${ }^{255}$ ) and 3289 (251SPCSVTYGKGTRSRK ${ }^{265}$ ) (Figure $1 \mathrm{C}$, blue and dark yellow, respectively) which are present in the 2 antiparallel and one ripped $\beta$ strand forming a resonant $\pi$ cationic niche between their $\mathrm{R}$ residues (cHABP $3289{ }^{262} \mathrm{R}$ and ${ }^{264} \mathrm{R}$ ) and $\mathrm{W}$ residues (cHABP $3287{ }^{247} \mathrm{~W}$ and ${ }^{250} \mathrm{~W}$ side-chain) where negatively-charged molecules bind, i.e. heparin and/or hepatocytes from HSPG and endothelial cells (Tossavainen et al., 2006; Patarroyo et al., 2016b).

Sporozoite essential for cell traversal-1 (SPECT-1) contains cHABPs 33372 $\left({ }^{81}\right.$ ASLEEVSDHVVQNISKYSLT $\left.{ }^{100}\right)$ and 33375 (142TDLILKKLKKLENVNKLIKY ${ }^{161}$ ) (Figure 3A, dark yellow and pale blue) forming a $\sim 750 \AA^{3}$ cavity where cholesterol binds (Hamaoka and Ghosh, 2014).

Several proteins are directly involved in Mrz attachment to and invasion of RBC during the erythrocyte stage; they are largely exposed to immune system attack during erythrocyte rupture and Mrz release. Most are enzymatically processed to expose their relevant structures, microneme stored, translocated to $\mathrm{Mrz}$ membrane and cleaved a few seconds before being exposed. Erythrocyte binding proteins (EBP) contain functional domains having similar 3D structure but bind to different receptors on the RBC which, in concert with and alternating with the reticulocyte homologous ( $R h)$ proteins, mediate invasion of RBC.

Regarding EBP, erythrocyte binding antigen 175 (EBA-175) is the prototype molecule, binding glycophorin A (GPA) glycans 2, 5 and 6 on RBC. cHABPs 1779 (500NIDRIYDKNLLMIKEHILAI ${ }^{519}$ ) and 1783 ( ${ }^{580 H R N K K N D K L Y R D E W W K V I K K ~}{ }^{599}$ ) (Figure 2A, pale blue and dark yellow) are located in the recombinant fragment entirely including region II (RII) containing fragment F1 

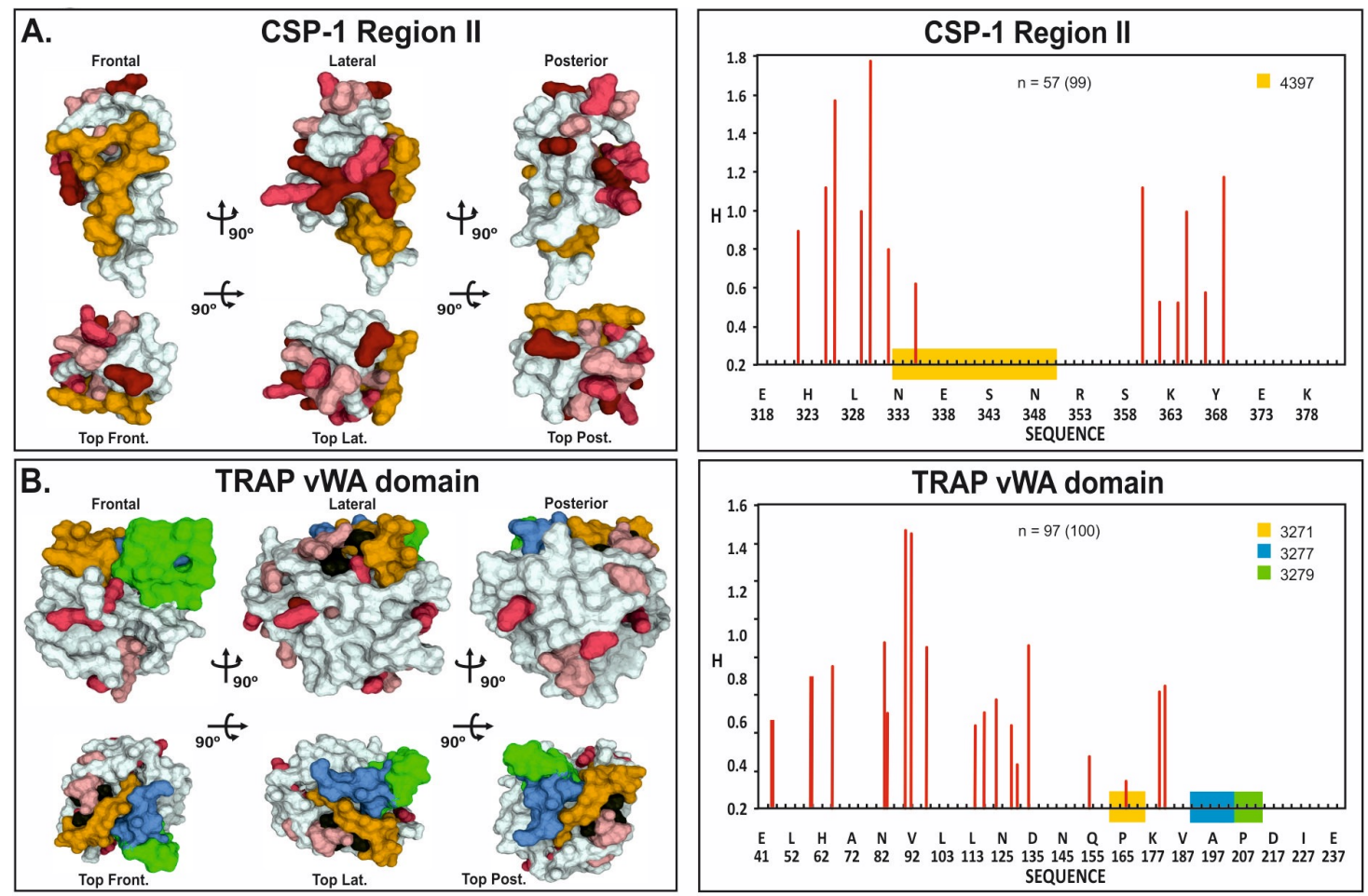

C. Frontal TRAP TSR domain

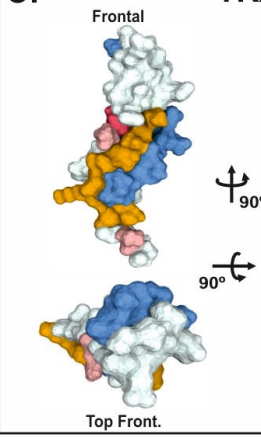

D.

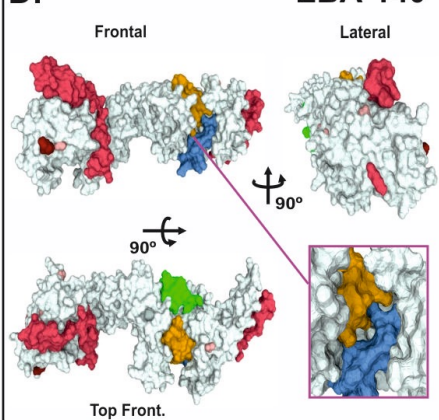

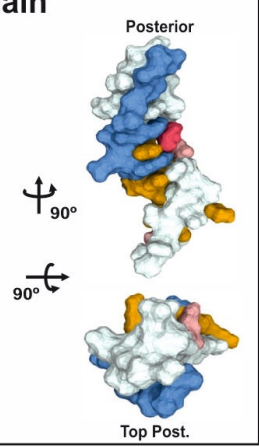
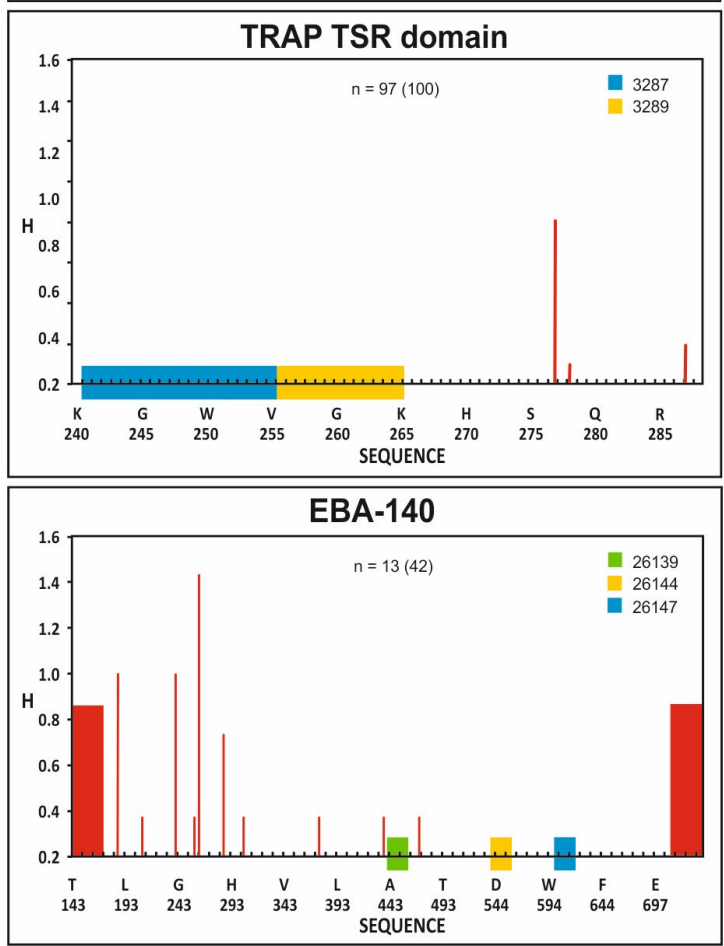
Figure 1. Three-dimensional representation and polymorphism analysis of CSP-1 C-terminal region, TRAP vWA domain, TRAP TSR domain and EBA-140 proteins.

LEFT panel: Different views of three-dimensional structures of the complete $P$. falciparum protein or its recombinants fragment (determined by $X$ ray crystallography) modelled in surfaces, displaying their corresponding cHABPs and polymorphic residues location (lesser to greater polymorphism being shown by pink, red and burgundy, respectively). (A) CSP-1 C-terminal region (PDB code 3VDK) (Doud et al., 2012) and CHABP 4397 (dark yellow) involved in binding to heparan sulphate proteoglycans (HSPGs). (B) TRAP vWA domain (PDB code 4F1J) (Pihlajamaa et al., 2013) and the location of cHABP 3271 (in dark yellow) containing the residues (in black) forming the metal ion-dependent adhesion site (MIDAS), cHABPs 3277 (in blue) and 3279 (in green) forming part of the HSPG binding site. (C) TRAP TSR domain (PDB code 2BBX) (Tossavainen et al., 2006), containing cHABPs 3289 (in dark yellow) and 3287 (in blue) which bind to heparan sulphate proteoglycans (HSPG) from hepatocytes and endothelial cells. (D) EBA-140 fragment (PDB code 4GF2) (Lin et al., 2012). The box displays the site where Hbonds are established between cHABPs 26144 (dark yellow) and 26147 (blue), the latter interacting with the acetamide group in sialic acid in RBC glycophorin C. cHABP 26139 (in green) is also shown; it interacts with the GPC carboxyl group.

RIGHT panel: (A, B, C and D) Representation of variability using Shannon's diversity index (in red bars) for each amino acid in the protein sequence. Each cHABP position is shown by coloured bars below each box. The top part of each box shows (in parenthesis) the total number of sequences taken from the redundant (NR) NCBI database; the amount of sequences used in multiple sequence alignment (selected or filtered by phylogenetic analysis) is shown to the left of the number in parenthesis. The numbers for the amino acids in the CSP-1 and TRAP TSR domain sequences are from the encoding system reported by Rodriguez et al., 2008.

and F2; cHABP 1783 binds to glycan 1 and includes residue ${ }^{590} \mathrm{R}$ that, together with residue ${ }^{174} \mathrm{D}$ from another region, forms a salt bridge to allow dimerisation in a "hand shake" form of EBA-175 and forms a large hole $(\sim 15 \AA$ diameter at its narrowest) where the protein component of GPA penetrates to establish stable binding to RBCs (Tolia et al., 2005).

Binding to glycophorin C (GPC) is mediated by EBA-140 whose monomer 3D structure shows two glycan binding sites where 26147 (601 LKNKETCKDYDKFQKIPQFL ${ }^{620}$ ) forms pocket 2 with cHABP 26144 (541DLADIIKGSDIIK DYYGKKM ${ }^{560}$ ). ${ }^{556} \mathrm{Y}$ establishes an $\mathrm{H}$-bond with GPC glycan 2 sialic acid acetamide (Figure 1D, dark yellow and blue) whilst cHABP 26139 ( ${ }^{441}$ DIASQINVNDLRGFGCNYKS ${ }^{460}$ ) (Figure 1D, green) interacts with the GPC backbone carboxyl group (Lin et al., 2012).

The only Rh molecule for which the 3D structure has been determined is Rh5; this interacts simultaneously with RBCs (differentially between humans and Aotus) and basigin. Regarding Rh5, c HABP 36727 (201GKYIAVDAFIK KINETYDKV ${ }^{220}$ ), together with cHABPs 36735 ( ${ }^{361}$ DEYIHKLILSVKSKNLNKDL $\left.{ }^{380}\right)$ and 36739 $\left({ }^{441} \mathrm{KIKLNIWRTFQKDELLKRIL}{ }^{460}\right)$, contact basigin C-terminus, while 36736 ( ${ }^{381}$ SDMTNILQQSELLLTNLNKK ${ }^{400}$ ) establishes H-bonds with 36735 ( ${ }^{361}$ DEYIHKLILSVK SKNLNKDL ${ }^{380}$ ) to create a niche where RBC bind (Arevalo-Pinzon et al., 2012; Chen, L. et al., 2014).

Concurrently with $\mathrm{Mrz}$ binding to RBC membrane, a group of 11 merozoite surface proteins (MSP) is used in conjunction to bind to and invade erythrocytes; some of them are anchored to the membrane via glicosylphosphatidylinositol (GPI) prosthetic group, others traverse the membrane and some others bind loosely to the membrane or to other MSP proteins (Rodriguez et al., 2008).

Most MSP (like MSP-1, MSP-6, MSP-7) are processed to expose functionally relevant sites; a panel of them contains epidermal growth factor (EGF)-like domains (MSP-1 - MSP-4, MSP-8 and MSP-10) in their C-terminal portion which have been suggested to be involved in protein-protein interactions (Gaur et al., 2004; Sanders et al., 2006). The most studied (MSP-1) is a $195 \mathrm{kDa}$ molecule, cleaved enzymatically into $83 \mathrm{kDa}, 38 \mathrm{kDa}, 30 \mathrm{kDa}$ and $42 \mathrm{kDa}$ fragments; the latter is further processed by a subtilisin (SUB), $\mathrm{Ca}^{2+}$-dependent enzymatic process into a $33 \mathrm{kDa}$ fragment (used to bind to spectrin on the cytoplasmic face of RBC, to be released later on the merosomes) and a $19 \mathrm{kDa}$ fragment remaining anchored to Mrz membrane (Pizarro et al., 2003) which contains cHABP 5501 ( ${ }^{1544}$ MLNISQHQCVKKQCPQNS ${ }^{1561}$ ) in its $\mathrm{N}$-terminal portion (Figure 2D, dark yellow), this being the only fragment found inside newly infected RBCs.

After becoming firmly attached to the RBC, the Mrz exposes a microneme protein apical membrane antigen 1 (AMA-1) which becomes translocated to the membrane and is then rapidly transferred to the apical pole where, in conjunction with other molecules (the rhoptry neck proteins 1-6), it forms the moving junction (MJ) complex which orientates the Mrz forwards to the apical pole to start penetrating RBC (Patarroyo et al., 2016b). This process is 

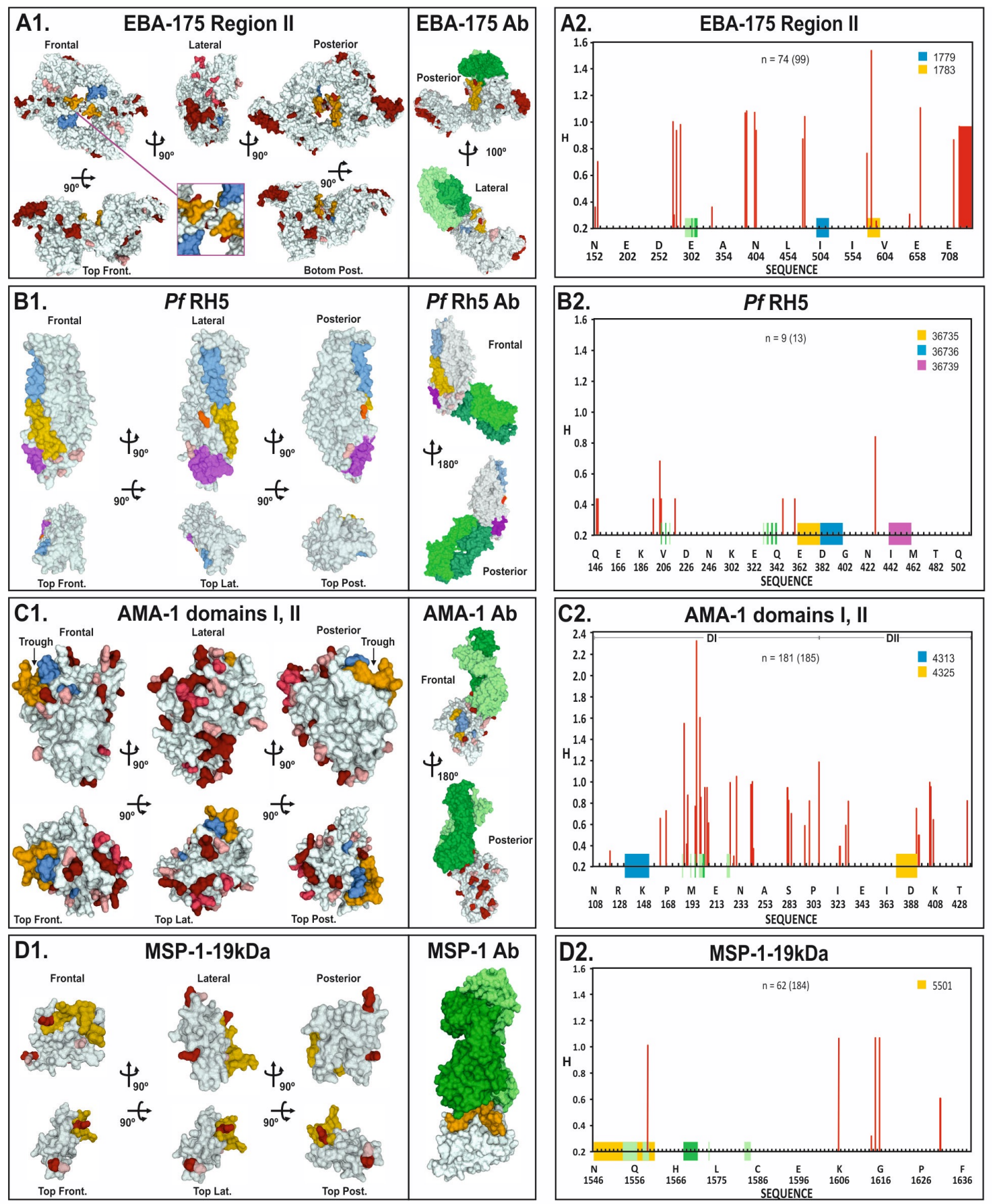
Figure 2. Three-dimensional representation and polymorphism analysis of EBA-175 RII, Pf Rh5, AMA-1 domain I, II and MSP-1 19 kDa proteins and their corresponding protein-monoclonal antibody complex.

LEFT panel: Surface representation of three-dimensional $P$. falciparum structures for the complete protein or its recombinants fragment (determined by X-ray crystallography), displaying their corresponding cHABPs and polymorphic residue location (in pink, red and burgundy, lesser to greater polymorphism, respectively). The MIDDLE panel: shows the 3D structures of $P$. falciparum proteins complexed with their respective monoclonal antibody (where the heavy chain is coloured pale green and the light chain in a darker green). (A1) EBA-175 RII recombinant fragment (PDB accession code 1ZRO) (Tolia et al., 2005) displaying the "hand shake" dimer formation (in the box), indicating the position of cHABPs 1779 (blue) and 1783 (dark yellow) that bind to RBCs. The elongated boxes alongside show the F1 domain EBA-175 RII fragment binding to the R218 mAb (PDB code 4K2U) (Chen, E. et al., 2013). (B1) Pf Rh5 (PDB code 4WAT) (Chen, L. et al., 2014) shows cHABPs 36735 (in dark yellow), 36736 (in blue) and 36739 (in purple) that bind to basigin. The crystal structure of Pf Rh5 bound to growthinhibitory monoclonal antibody fragments 9AD4 (PDB code 4UOR) is also shown (Wright et al., 2014). (C1) Pf AMA-1 recombinant fragment (PDB accession number 1Z40) (Bai et al., 2005) containing domains I (residues 108-308) and II (residues 309-436) and the location of RBCbinding CHABPs 4313 (blue) and 4325 (dark yellow), displaying the trough where a still undetermined RBC receptor binds. A view of the nonpolymorphic and polymorphic face of this protein is also shown, as well as the 3D structure of Pf AMA-1 complexed with $1 \mathrm{~F} 9 \mathrm{mAb}$ (PDB accession number 2Q8A) (Coley et al., 2007). (D1) MSP-1 19 kDa fragment (PDB code 10B1) where cHABP 5501 (in dark yellow) was located; it interacts with band 3. At the side is shown the position where monoclonal antibody G.17.12 interacts with the MSP-1 19 kDa fragment (PDB code 10B1) (Pizarro et al., 2003).

RIGHT panel: The boxes (A2, B2, C2 and D2) give a representation of variability using Shannon's diversity index (in red bars) for each amino acid in the proteins' sequence. The positions where the interaction of the proteins with mAb residues takes place are shown on the axis below the Figure, according to the colour code. The position of each cHABP is shown by coloured bars below each box. The positions where heavy and light chain $\mathrm{mAb}$ interactions take place with each protein are shown in green (the heavy chain in pale green and the light chain in a darker green). The top part of each box shows (in parenthesis) the total number of sequences taken from the redundant (NR) NCBI database; the amount of sequences used in multiple sequence alignment (selected or filtered by phylogenetic analysis) is shown to the left of the number in parenthesis. The numbers for the amino acids in the EBA-175 and MSP-1 $19 \mathrm{kDa}$ sequences are from the encoding system reported by Rodriguez et al., 2008.

mediated (after prodomain removal) by AMA-1 domains I and II where cHABPs 4313 ( ${ }^{134}$ DAEVAGTQYRLPSGKCPVFG ${ }^{153}$ ) (DI) and $4325\left({ }^{374}\right.$ MIKSAFLPTGAFKADRYKSH $\left.{ }^{393}\right)$ (DII) form a trough or channel stabilised by $\mathrm{H}$-bonds where an as-yet-unknown receptor binds (Figure 2C, blue and dark yellow) (Bai et al., 2005).

Many other proteins participate in invasion but, as mentioned before, only those for which their 3D structure has been determined (except for extremely polymorphic $P f$ EMP-1) are shown here.

Serine repeat antigen 5 contains cHABPs 6746 ( ${ }^{581}$ DQGNCDTSWIFASKYHLETI ${ }^{600}$ ) and 6754 $\left({ }^{741} \mathrm{KKVQNLCGDDTADHAVNIVG}^{760}\right)$ in its 50 $\mathrm{kDa}$ fragment, forming a trough or channel stabilised by an $\mathrm{H}$-bond where non-canonical cysteine protease enzymatic activity is located (Figure 3B, pale blue and dark yellow) (Hodder et al., 2009).

\section{Genetic polymorphism, the most commonly used escape mechanism}

Time is relative for both host and parasite. While for humans it takes at least one generation (25 years) to fix a mutation, it takes the $P$. falciparum parasite only 48 hours (one of its generations) to do so; the parasite tries to fix this many times during a single cycle and this can be increased by sexual mating in the mosquito's midgut. Therefore the successful mutations observed during genetic polymorphism analysis are only the tip of the iceberg; however, some common structural patterns begin to appear as a consequence of the structural analysis of both host and parasite.

\section{D structural analysis}

X-ray crystallography 3D structural analysis of $P$. falciparum protein recombinant fragments has revealed that the $3 \mathrm{D}$ structure of our cHABPs determined by ${ }^{1} \mathrm{H}-\mathrm{NMR}$ has strikingly similar $3 \mathrm{D}$ structure with a protein's fragments containing the same aa sequence regardless of whether they be $\alpha$-helical, $\beta$-turns, $\beta$-sheet or random structures, since they can be superimposed with RMSD $<0.980 \AA$. Most cHABPs are components of channels, troughs, cavities or holes; such active sites perform critical biological functions like binding to receptor molecules or enzymatic activities. CHABPs are located in particular and specific protein regions.

Furthermore, as can be seen in all Figures, despite the distance in aa sequence (sometimes being as much as $\sim 250$ residues apart), these cHABPs form niches or troughs where receptor molecules bind, as occurs with AMA- 14313 $\left({ }^{134}\right.$ DAEVAGTQYRLPSGKCPVFG $\left.{ }^{153}\right)$ and 4325 ( ${ }^{374}$ MIKSAFLPTGAFKADRYKSH ${ }^{393}$ ) (Bai et al., 

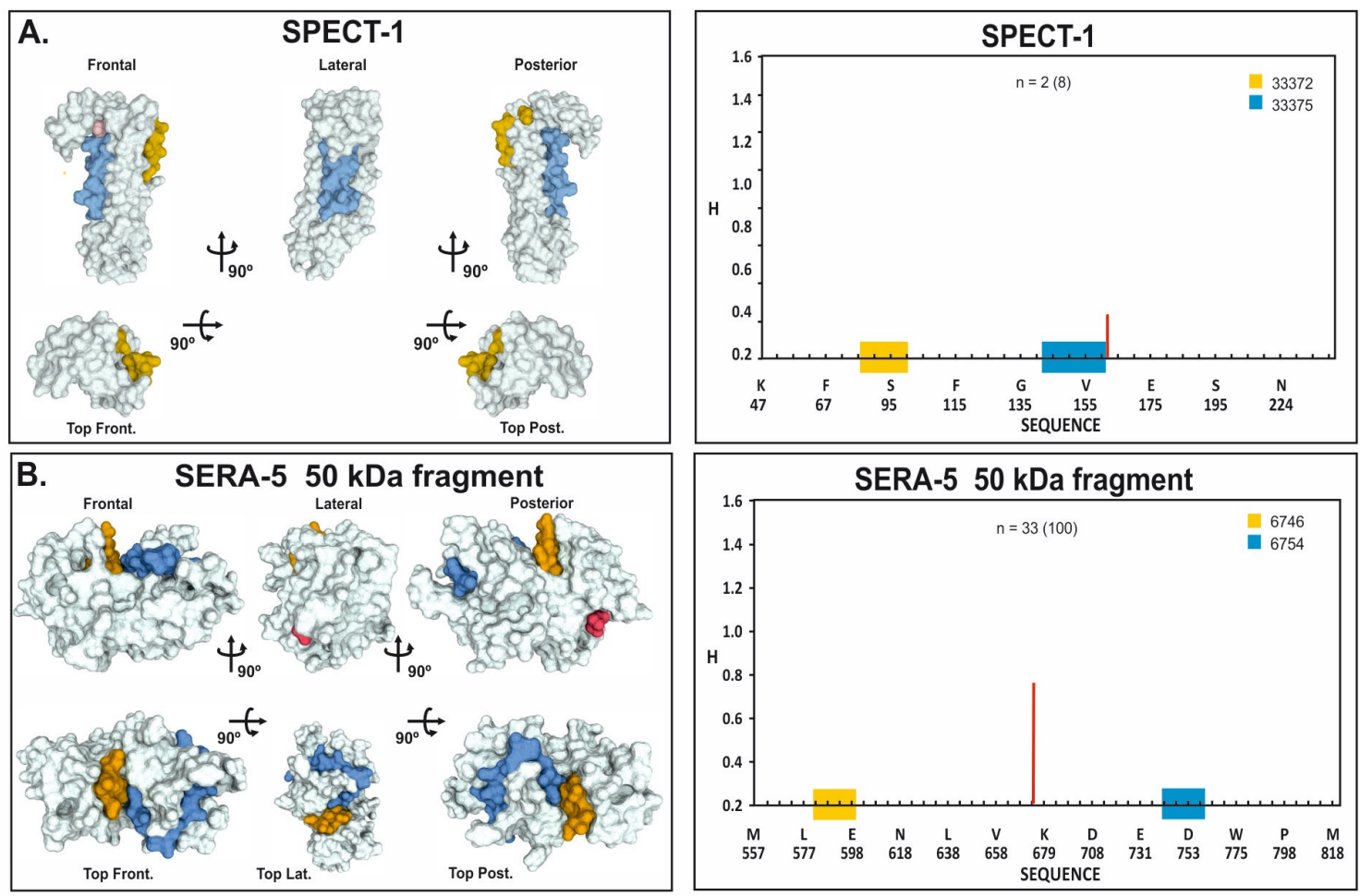

Figure 3. Three-dimensional representation and polymorphism analysis of SPECT-1 and SERA-5 $50 \mathrm{kDa}$ fragment proteins.

LEFT panel: Different views of three-dimensional structures of $P$. falciparum of the complete protein or its recombinants fragment (determined by X-ray crystallography) modelled in surfaces, displaying their corresponding cHABPs and polymorphic residues location (in pink, red and burgundy, lesser to greater polymorphism, respectively).

(A) SPECT-1 (PDB accession code 4U5A) (Hamaoka and Ghosh, 2014) and cHABPs 33372 (dark yellow) and 33375 (blue). (B) SERA-5 recombinant fragment (PDB code $3 \mathrm{CH} 2$ ) (Hodder et al., 2009) and the localisation of cHABPs 6746 (in dark yellow) and 6754 (in blue) whose $\mathrm{H}$ bonds form the catalytic triad.

RIGHT panel: (A, B, C and D) Representation of variability using Shannon's diversity index for each amino acid in the protein sequence. cHABP position is shown coloured in the part below the Figure. The top part of each box shows (in parenthesis) the total number of sequences taken from the redundant (NR) NCBI database; the amount of sequences used in multiple sequence alignment (selected or filtered by phylogenetic analysis) is shown to the left of the number in parenthesis.

2005). These cHABPs could also be sequential, as occurs with TRAP cHABPs 3287 (241TASCGVWDEWSPYSV ${ }^{255}$ ) and 3289 $\left({ }^{251}\right.$ SPCSVTYGKGTRSRK $\left.{ }^{265}\right)$ forming a positively-charged trough where negativelycharged receptors bind, like heparin and HSPG (Tossavainen et al., 2006). Some others fold in such a way that they themselves can create the cavity or pocket where the cholesterol molecule binds, as occurs with CSP-1 4397 (331IQNSLSTEWSPCSVTCGNGI ${ }^{350}$ ) cHABP (Doud et al., 2012) and TRAP VWA domain cHABP 3279 ( ${ }^{201}$ FLVGCHPSDGKCNLY ${ }^{215}$ ) (Pihlajamaa et al., 2013), unlike SPECT-1
cHABPS $33372\left({ }^{81}\right.$ ASLEEVSDHVVQNIS KYSLT $\left.^{100}\right)$ and 33375 (142TDLILKKLKKLENV NKLIKY ${ }^{161}$ ) that, despite being on the opposite side of the molecule, form part of a cavity which has been suggested as cholesterol binding site on host cell membrane (Hamaoka and Ghosh, 2014). Some cHABPs interact with each other, such as EBA-140 cHABPs 26139 $\left({ }^{441}\right.$ DIASQINVNDLRGFGCNYKS $\left.{ }^{460}\right), 26144$ ( ${ }^{541}$ DLADIIKGSDIIKDYYGKKM ${ }^{560}$ ) and 26147 (601 ${ }^{6 K N K E T C K D Y D K F Q K I P Q F L ~}{ }^{620}$ ) as they establish an $\mathrm{H}$-bond with the glycophorin $\mathrm{C}$ glycan 2 receptor (Lin et al., 2012) and like SERA-5 cHABPs 6746 ( ${ }^{581}$ DQGNCDTSWIFAS 
KYHLETI $\left.{ }^{600}\right)$ and $6754\left({ }^{741}\right.$ KKVQNLCGDDTAD $\mathrm{HAVNIVG}^{760}$ ) forming $\mathrm{H}$-bonds as part of an enzymatic triad and constituting the noncanonical serine protease active site (Hodder et al., 2009). There are also intercalated hypervariable regions, as occurs with Rh5 cHABPs 36727 (201GKYIAVDAFIKKINET YDKV $\left.{ }^{20}\right)$ and 36735 (361DEYIHKLILSVKSKN LNKDL $^{380}$ ) establishing contact with basigin (Chen, L. et al., 2014), and another such as MSP-1 cHABP 5501 ( ${ }^{1544}$ MLNISQHQCVKKQC $P Q N S^{1561}$ ), having a variable aa in its C-terminus and interacting with the band 3 sequence (Pizarro et al., 2003).

Regarding EBL cHABPs, there is cadence where $\sim 80 \pm 20$ residues are separated, as occurs in EBA-175 and EBA-140 (and EBA-181, though lacking $3 \mathrm{D}$ structure), suggesting that $\mathrm{EBL}$ proteins have very similar structural characteristics due to the presence of cysteinerich Duffy binding-like (DBL) domains which are responsible for creating multiple binding sites for recognition and binding to erythrocyte receptor (Tolia et al., 2005; Treeck et al., 2006). This occurs with EBA-175 cHABP $1783\left({ }^{580} \mathrm{HRNK}\right.$ KNDKLYRDEWWKVIKK ${ }^{599}$ ) that binds to glycophorin A receptor on RBC and EBA-140 cHABP 26144 ( ${ }^{541}$ DLADIIKGSDIIKDYYGKKM ${ }^{560}$ ) that interacts with $\mathrm{RBC}$ glycophorin $\mathrm{C}$.

\section{Hypervariable regions (Hv)}

Despite the fact that aa sequence analysis can only give a rough idea regarding hypervariable region location, only 3D structural analysis can localise them with certainty in the molecule.

It was decided to search known databases and use software for defining $\mathrm{Hv}$ regions in proteins suggested as promising vaccine candidates as they have been shown to have a proven functional role in the parasite. An initial search was thus made for $P$. falciparum 3D7 strain sequences in the PlasmoDB Plasmodium Genomics Resource database (Aurrecoechea et al., 2009) for each protein. The resulting proteins were taken as query for searches regarding available sequences of different parasite strains using the protein BLAST tool (Altschul et al., 1997) from the non-redundant (NR) NCBI database. MUSCLE software (Edgar, 2004) was used for multiple sequence alignments of the selected sequences (for each protein).
The aa sequence variability (from the multiple sequence alignment for each of the aforementioned proteins) was calculated by using the Protein Variability Server (PVS) (Garcia-Boronat et al., 2008) which uses the Shannon diversity index or Shannon entropy $(\mathrm{H})$ as means of measuring variability, represented by the right-hand part of Figures 1,2 and 3 which, in turn, were used for the 3D modelling shown on the left-hand side of the same Figures. Such modelling involved using Visual Molecular Dynamics (VMD) molecular modelling software (Humphrey et al., 1996); the atomic coordinates of each 3D structure for the molecules reported in the Protein Data Bank (PDB, 2016) were taken as reference. The PDB accession codes are indicated in the Figure legends.

To aid understanding, hypervariable regions are coloured red in Figures 1 to 3, pink showing the least polymorphism and the deeper the red the most variable. cHABPs by definition DO NOT have variable aa, except for CSP-1 4397 $\left({ }^{331} \mid\right.$ QNSLSTEWSPCSVTCGNG| $\left.{ }^{350}\right)$ in the $2^{\text {nd }}$ and $5^{\text {th }}$ residues, EBA-175 $1783\left({ }^{580} \mathrm{HRNK}\right.$ KNDKLYRDEWWKVIKK $\left.{ }^{599}\right)$ in its $5^{\text {th }}$ residue and MSP-1 19 kDa 5501 ( ${ }^{1544}$ MLNISQHQCVKKQ CPQNS ${ }^{1561}$ ) in its antepenultimate residue (highlighted in bold). All of them have very limited polymorphism (only one or a maximum of three aa mutations); therefore, these residues were not included/removed from the sequence regarding modified HABP design fragments (i.e. further modifying the conserved part) (Patarroyo and Patarroyo, 2008).

\section{Monoclonal antibody (mAb) reactivity}

It has been suggested that mouse anti-EBA-175 IgG1 R217 mAb can inhibit RBC GPA binding but, according to EBA-175 aa sequence, its binding site is close to the dimerisation site formed by ${ }^{590} \mathrm{R}$ and ${ }^{174} \mathrm{D}$; interestingly, while IgG1 R217 mAb has $10-100 \mu \mathrm{g} / \mathrm{mL}$ growth inhibitory capacity $\left(\mathrm{IC}_{50}\right)$, binding to a conformational epitope located between the $F 2 \beta$ finger (477-485) and an $\alpha$-helix (residues 561-567), this mAb DOES NOT inhibit GPA glycan binding but has steric hindrance or impedance to EBA-175 dimerisation (Chen, E. et al., 2013). Another $\mathrm{mAb}$, (R218) binding to residues ${ }^{304} \mathrm{KNNINN}^{309}$ far away from cHABPs 1779 (500NIDRIYDKNLLMIKEHILAI ${ }^{519}$ ) and 1783 ( ${ }^{580}$ HRNKKNDKLYRDEWWKVIKK ${ }^{599}$ ) does not inhibit RBC invasion (Figure 2A) (Chen, E. et al., 2013). It is clear that none of the aforementioned 
mAb or human antibodies elicited after multiple infections bind to and block cHABP 1779 ( ${ }^{500}$ NIDRIYDKNLLMIKEHILAI ${ }^{519}$ ) and 1783 (580HRNKKNDKLYRDEWWKVIKK ${ }^{599}$ ) binding sequences to GPA glycans to impede RBC invasion.

In the EBP, Rh5 mouse QA1 mAb blocks Pf Rh5basigin binding and parasite growth, binding to residues ${ }^{346} \mathrm{YNNNF}^{351} \mathrm{EN}^{353} \mathrm{TN}^{354}$ and ${ }^{196} \mathrm{KS}^{197}$ (Wright et al., 2014) variable aa sequences close to but not involving cHABPs 36735 ( ${ }^{361}$ DEYIHKLILSVKSKNLNKDL $\left.{ }^{380}\right)$ and 36739 $\left({ }^{441} \mathrm{KIKLNIW}\right.$ RTFQKDELLKRIL $\left.{ }^{460}\right)$ (Figure 2B).

The most polymorphic AMA-1 protein has a large number of hypervariable regions and a large set of $\mathrm{mAb}$ able to mediate parasite growth inhibition; however, the 3D structures of just a few $\mathrm{mAb}$ have been described to date. 1F9 mAb (Coley et al., 2007) binds to a solvent-exposed polymorphic hydrophobic trough where RON6 protein aa sequences bind to cooperate in RBC invasion. This variable hydrophobic trough spans from residues ${ }^{183} \mathrm{~F}$ to ${ }^{235} \mathrm{~K}$, far away from our cHABPs 4313 (134DAEVAGTQYRLPSGKC PVFG $\left.^{153}\right)$ and $4325\left({ }^{374}\right.$ MIKSAFLPTGAFKAD $\mathrm{RYKSH}^{393}$ ) (Figure 2C).

Regarding the $19 \mathrm{kDa}$ MSP-1-derived fragment, a Fab fragment from mouse G17.12 mAb was obtained that does not inhibit Mrz invasion of RBC nor MSP-1 in X-ray crystallography structure; when it was complexed with the recombinant $19 \mathrm{kDa}$ fragment, it bound cHABP 5501 ( $\left.{ }^{1544} \mathrm{MLNISQHQCVKKQCPQNS}{ }^{1561}\right)$ in its C-terminus residues (Figure 2D), ${ }^{1553} \mathrm{VKKQ}{ }^{1556}$ the last being a relatively polymorphic residue, having only $\mathrm{Q} / \mathrm{H} / \mathrm{K}$ mutations (Pizarro et al., 2003).

\section{Antibody reactivity from individuals living in endemic areas}

It has long been thought that antibodies' fine specificity rather than antibody titres are more important regarding protection as it has been suggested that some of them play a role in protein processing as occurs with some MSP-1 $19 \mathrm{kDa}$ reactive antibodies, named inhibitory antibodies since a very small set of them inhibits Mrz invasion of RBCs and MSP-1 processing, while some others block such inhibition, named blocking antibodies (Omosun et al., 2009).
Chemical shift perturbation analysis of TROSY spectra by NMR cross-saturation techniques (Morgan et al., 2005) revealed Fab fragments from two inhibitory monoclonal antibodies (mAb 12.8 and $m A b$ 12.10) interacting with epitopes located in the C-terminal region of MSP-1 19 $\mathrm{kDa}$. Competition assays with some other monoclonal antibodies, like 1E1, 7.5, 8A12 and $2 \mathrm{~F} 10$, and $P$. falciparum malaria infected-sera from Ugandan and Wolof, Mandinka and Fula Gambian children have shown that Gambian children (in whose sera antibodies competed by blocking 1E1 mAb binding to MSP-1 $19 \mathrm{kDa}$ recombinant protein) were significantly less likely to become infected by malaria during the high transmission season. This $1 \mathrm{E} 1 \mathrm{mAb}$ reacts with our cHABP $5501\left({ }^{1544} \mathrm{MLNISQHQCVKKQCP}\right.$ QNS ${ }^{1561}$ ) residues ${ }^{1547},{ }^{1551} \mathrm{Q}$ and ${ }^{1552} \mathrm{C}$, while Ugandan children's sera competition assays reactivity were associated with low parasitaemia during infection; this was particularly associated with 12.8, 12.10 and $2 \mathrm{~F} 10 \mathrm{mAb}$ (whose reactivity was directed towards the $5501\left({ }^{1544} \mathrm{MLNISQHQ}\right.$ CVKKQCPQNS ${ }^{1561}$ ) C-terminus or following residues) (Uthaipibull et al., 2001). The foregoing suggests that protection against high density parasitaemia could be associated with antibody concentration or affinities against this MSP-1 19 $\mathrm{kDa}$ portion (Okech et al., 2004). This data clearly stresses the importance of specifically choosing the appropriate sequence for vaccine development.

Antibodies to AMA-1 have been associated with preventing parasite invasion of host cells in vitro and human antibodies to AMA-1 can inhibit blood-stage replication of $P$. falciparum.

This protein has been divided into three domains (I, II and III), where polymorphic sites are located having inhibitory epitope function, such as antigenic escape mechanisms. These polymorphic residues surround a hydrophobic pocket suggested as being critical for AMA-1 function. Domain I has the major polymorphic sites, grouped into 3 clusters (C1, C2 and C3); regarding C1-L (loop containing residues 196, 197, 199, 200, 201, 204, 206 and 207), 1F9 mAb binds in loop Id and most human antibodies react against it (Bai et al., 2005; Dutta et al., 2007; Takala et al., 2009; Ouattara et al., 2013; Harris et al., 2014). However, once the epitope has been recognised it inhibits in vitro invasion in a strain-specific manner, as in the case of $1 \mathrm{~F} 9$ $\mathrm{mAb}$ inhibiting in vitro growth of 3D7 and D10 
parasite strains, but not HB3 or W2mef where a single aa substitution at the most highly polymorphic site (residue 197) in AMA-1 abolishes 1F9 mAb binding (Coley et al., 2006), thereby limiting the effectiveness of these antigens as vaccine components.

Through studies in two Kenyan villages, Chonyi and Ngerenya (Mugyenyi et al., 2013), it has been found that individuals living in malariaendemic areas have naturally-acquired antibodies to AMA-1 polymorphic epitopes targeting the invasion-inhibiting $1 \mathrm{~F} 9$ epitope and non-inhibitory $2 \mathrm{C} 5$ epitope. These antibodies are acquired through increasing exposure to the disease and have shown some association with a reduced risk of clinical malaria. This shows that 1F9 antibody prevalence was low in both populations (despite the high prevalence of antibodies against the AMA-1 ectodomain) and lower than prevalence of antibodies against the 2C5 epitope. 1F9 mAb affinity appears to be higher than that of $2 \mathrm{C} 5$; therefore, only sera having high affinity antibodies may inhibit 1F9 $\mathrm{mAb}$ binding in competition ELISA (Mugyenyi et al., 2013). The greater levels and prevalence of $2 \mathrm{C} 5$ reactivity observed may partly reflect the lower affinity of 2C5 mAb, thereby allowing serum antibodies to compete more readily for binding; this suggests that sera having other acquired high affinity antibodies may inhibit (by competition or blocking) 1F9 mAb binding, avoiding their inhibitory role and reflecting their polymorphic nature (Mugyenyi et al., 2013).

EBA-175 binds to glycophorin A on the surface of human erythrocytes during Mrz invasion; a region identified as RII within EBA-175 contains two Duffy binding-like (DBL) domains called F1 and F2. EBA-175 RII dimer interface consists of two loops from within each monomer, identified as the F1 and F2 $\beta$-fingers; these contact depressions in the opposing monomers in a similar manner. These domains are responsible for binding glycophorin A in a sialic aciddependent manner and whose function could be blocked by antibodies (Ambroggio et al., 2013; Chen, E. et al., 2013).

A sero-epidemiological study in holoendemic region of the Nyanza province in western Kenya (Ohas et al., 2004) showed that anti-EBA-175 RII antibodies are highly prevalent and have high levels in individuals at the study site; however, naturally acquired anti-EBA-175 RII antibodies conferring immunity against clinical malaria do not appear, suggesting that, although antibodies against EBA-175 RII may be effective in suppressing some wild parasite strains (Ohas et al., 2004), EBA-175 RII is unlikely to be effective as a monovalent antimalarial vaccine, perhaps due to allelic heterogeneity and/or the presence of sialic acid-independent strains (Ohas et al., 2004). Like the previous case, others may acquire antibodies which inhibit binding to receptors, such as R217 and R218 epitopes, and prevent parasite growth.

It has been reported that conserved EBA-175 regions III-V have been able to induce antibodies that inhibit Mrz invasion of diverse parasite strains, including those reliant on invasion pathways regardless of EBA-175 function. However, this region is specifically dimorphic and no functional role has yet been identified for it (Ware et al., 1993; Healer et al., 2013; Persson et al., 2013).

On the other hand, EBA-175 RII (where cHABPs 1779 and 1783 are located) is recognised by antibodies in individuals having naturally acquired immunity in an age-dependent manner and inhibits invasion of $P$. falciparum clinical isolates to some degree (Okenu et al., 2000; El Sahly et al., 2010; Badiane et al., 2013; Irani et al., 2015). High-titre antibodies against EBA-175 RII are associated with protection from clinical malaria in children (Okenu et al., 2000; McCarra et al., 2011), although such association is not clear in some studies or has not been observed in groups having low incidence of disease (Osier et al., 2008; Richards et al., 2010)

It has been suggested that EBA-175 RII polymorphism has shown immune selection aimed at maintaining genetic diversity in parasite populations. This polymorphism may contribute towards the lack of association with protective immunity in some cohort studies, depending on which strain the antigen used in these studies originated from, and would affect the ability of antibodies specific for EBA-175 to block invasion (Baum et al., 2003; Jiang et al., 2011; Healer et al., 2013). However, invasion inhibition by antibodies to 3D7 EBA-175 RII is unaffected by polymorphisms occurring in region II, suggesting that this region may bind with greater avidity than some other ligands (Jiang et al., 2011). 


\section{Conclusions}

The results presented in this manuscript have revealed that conserved high activity binding peptides (cHABPs) from a parasite's most relevant proteins are components of channels, troughs, cavities or holes; such active sites perform critical biological functions such as binding to receptor molecules or the enzymatic activities necessary for host cell invasion.

The forgoing analysis of the $3 D$ structure has demonstrated that these cHABPs are located in specific protein regions, spatially located far away from highly immunogenic regions, thereby suggesting that microbes can allocate functionally relevant cHABPs in areas remote from the hypervariable regions as a mechanism for evading immune pressure. This is so that mAb cannot interact with them or (more importantly) impede their functions by steric hindrance or blocking (a very smart mechanism for escaping immune pressure), rendering these regions useless for vaccine development. The forgoing means that, in spite of these cHABPs' functionally-relevant structures being immunologically silent, they are targets for inducing a protective, strain-transcending immune response to impede, block or destroy parasite functions once some critical host cell binding residues have been appropriately modified. This makes them excellent candidate components for multi-epitope, multistage, minimal subunit based, chemically-synthesised vaccine development.

\section{Acknowledgements}

This research was financed by the Colombian Science, Technology and Innovation Department (Colciencias) through contract RC\#0309-201. We would like to thank the Universidad del Rosario in Bogotá for financing this work.

\section{References}

Altschul, S.F., Madden, T.L., Schaffer, A.A., Zhang, J., Zhang, Z., Miller, W., and Lipman, D.J. (1997). Gapped BLAST and PSI-BLAST: a new generation of protein database search programs. Nucleic Acids Res. 25, 3389-3402.

Ambroggio, X., Jiang, L., Aebig, J., Obiakor, H., Lukszo, J., and Narum, D.L. (2013). The epitope of monoclonal antibodies blocking erythrocyte invasion by Plasmodium falciparum map to the dimerization and receptor glycan binding sites of EBA-175. PloS one 8 , e56326.
Arevalo-Pinzon, G., Curtidor, H., Munoz, M., Patarroyo, M.A., Bermudez, A., and Patarroyo, M.E. (2012). A single amino acid change in the Plasmodium falciparum RH5 (PfRH5) human RBC binding sequence modifies its structure and determines species-specific binding activity. Vaccine 30, 637-646.

Aurrecoechea, C., Brestelli, J., Brunk, B.P., Dommer, J., Fischer, S., Gajria, B., Gao, X., Gingle, A., Grant, G., Harb, O.S., Heiges, M., Innamorato, F., lodice, J., Kissinger, J.C., Kraemer, E., Li, W., Miller, J.A., Nayak, V., Pennington, C., Pinney, D.F., Roos, D.S., Ross, C., Stoeckert, C.J., Jr., Treatman, C., and Wang, H. (2009). PlasmoDB: a functional genomic database for malaria parasites. Nucleic Acids Res. 37, D539-543.

Badiane, A.S., Bei, A.K., Ahouidi, A.D., Patel, S.D., Salinas, N., Ndiaye, D., Sarr, O., Ndir, O., Tolia, N.H., Mboup, S., and Duraisingh, M.T. (2013). Inhibitory humoral responses to the Plasmodium falciparum vaccine candidate EBA-175 are independent of the erythrocyte invasion pathway. Clin. Vacc. Immunol. : CVI 20, 1238-1245.

Bai, T., Becker, M., Gupta, A., Strike, P., Murphy, V.J., Anders, R.F., and Batchelor, A.H. (2005). Structure of AMA1 from Plasmodium falciparum reveals a clustering of polymorphisms that surround a conserved hydrophobic pocket. Proc. Natl. Acad. Sci. USA 102, 12736-12741.

Baum, J., Thomas, A.W., and Conway, D.J. (2003). Evidence for diversifying selection on erythrocyte-binding antigens of Plasmodium falciparum and P. vivax. Genetics 163, 1327-1336.

Coley, A.M., Gupta, A., Murphy, V.J., Bai, T., Kim, H., Foley, M., Anders, R.F., and Batchelor, A.H. (2007). Structure of the malaria antigen AMA1 in complex with a growth-inhibitory antibody. PLoS pathogens 3, 1308-1319.

Coley, A.M., Parisi, K., Masciantonio, R., Hoeck, J., Casey, J.L., Murphy, V.J., Harris, K.S., Batchelor, A.H., Anders, R.F., and Foley, M. (2006). The most polymorphic residue on Plasmodium falciparum apical membrane antigen 1 determines binding of an invasioninhibitory antibody. Infection Immunity 74 , 2628-2636.

Curtidor, H., Vanegas, M., Alba, M.P., and Patarroyo, M.E. (2011). Functional, immunological and three-dimensional analysis of chemically synthesised sporozoite peptides 
as components of a fully-effective antimalarial vaccine. Curr Med Chem 18, 4470-4502.

Chen, E., Paing, M.M., Salinas, N., Sim, B.K., and Tolia, N.H. (2013). Structural and functional basis for inhibition of erythrocyte invasion by antibodies that target Plasmodium falciparum EBA-175. PLoS pathogens 9, e1003390.

Chen, L., Xu, Y., Healer, J., Thompson, J.K., Smith, B.J., Lawrence, M.C., and Cowman, A.F. (2014). Crystal structure of PfRh5, an essential P. falciparum ligand for invasion of human erythrocytes. eLife 3.

Doud, M.B., Koksal, A.C., Mi, L.Z., Song, G., Lu, C., and Springer, T.A. (2012). Unexpected fold in the circumsporozoite protein target of malaria vaccines. Proc. Natl. Acad. Sci. USA 109, 7817-7822.

Dutta, S., Lee, S.Y., Batchelor, A.H., and Lanar, D.E. (2007). Structural basis of antigenic escape of a malaria vaccine candidate. Proc. Natl. Acad. Sci. USA 104, 12488-12493.

Edgar, R.C. (2004). MUSCLE: multiple sequence alignment with high accuracy and high throughput. Nucleic Acids Res. 32, 1792-1797.

El Sahly, H.M., Patel, S.M., Atmar, R.L., Lanford, T.A., Dube, T., Thompson, D., Sim, B.K., Long, C., and Keitel, W.A. (2010). Safety and immunogenicity of a recombinant nonglycosylated erythrocyte binding antigen 175 Region II malaria vaccine in healthy adults living in an area where malaria is not endemic. Clin. Vacc. Immunol. : CVI 17, 1552-1559.

Garcia-Boronat, M., Diez-Rivero, C.M., Reinherz, E.L., and Reche, P.A. (2008). PVS: a web server for protein sequence variability analysis tuned to facilitate conserved epitope discovery. Nucleic Acids Res. 36, W35-41.

Gaur, D., Mayer, D.C., and Miller, L.H. (2004). Parasite ligand-host receptor interactions during invasion of erythrocytes by Plasmodium merozoites. Int. J. Parasitol. 34, 1413-1429.

Hamaoka, B.Y., and Ghosh, P. (2014). Structure of the essential Plasmodium host cell traversal protein SPECT1. PloS one 9, e114685.

Hardy, T. (1874). Far From The Madding Crowd (Smith, Elder and Co. First edn).

Harris, K.S., Adda, C.G., Khore, M., Drew, D.R., Valentini-Gatt, A., Fowkes, F.J., Beeson, J.G., Dutta, S., Anders, R.F., and Foley, M. (2014). Use of immunodampening to overcome diversity in the malarial vaccine candidate apical membrane antigen 1. Infection Immunity 82, 4707-4717.
Healer, J., Thompson, J.K., Riglar, D.T., Wilson, D.W., Chiu, Y.H., Miura, K., Chen, L., Hodder, A.N., Long, C.A., Hansen, D.S., Baum, J., and Cowman, A.F. (2013). Vaccination with conserved regions of erythrocyte-binding antigens induces neutralizing antibodies against multiple strains of Plasmodium falciparum. PloS one 8, e72504.

Hodder, A.N., Malby, R.L., Clarke, O.B., Fairlie, W.D., Colman, P.M., Crabb, B.S., and Smith, B.J. (2009). Structural insights into the protease-like antigen Plasmodium falciparum SERA5 and its noncanonical active-site serine. Journal of molecular biology 392, 154-165.

Humphrey, W., Dalke, A., and Schulten, K. (1996). VMD: visual molecular dynamics. Journal of molecular graphics 14, 33-38, 27-38.

Irani, V., Ramsland, P.A., Guy, A.J., Siba, P.M., Mueller, I., Richards, J.S., and Beeson, J.G. (2015). Acquisition of Functional Antibodies That Block the Binding of Erythrocyte-Binding Antigen 175 and Protection Against Plasmodium falciparum Malaria in Children. Clinical infectious diseases : an official publication of the Infectious Diseases Society of America 61, 1244-1252.

Jiang, L., Gaur, D., Mu, J., Zhou, H., Long, C.A., and Miller, L.H. (2011). Evidence for erythrocyte-binding antigen 175 as a component of a ligand-blocking blood-stage malaria vaccine. Proc. Natl. Acad. Sci. USA 108, 7553-7558.

Lin, D.H., Malpede, B.M., Batchelor, J.D., and Tolia, N.H. (2012). Crystal and solution structures of Plasmodium falciparum erythrocyte-binding antigen 140 reveal determinants of receptor specificity during erythrocyte invasion. J. Biol. Chem. 287, 36830-36836.

McCarra, M.B., Ayodo, G., Sumba, P.O., Kazura, J.W., Moormann, A.M., Narum, D.L., and John, C.C. (2011). Antibodies to Plasmodium falciparum erythrocyte-binding antigen-175 are associated with protection from clinical malaria. The Pediatric infectious disease journal 30, 1037-1042.

Morgan, W.D., Frenkiel, T.A., Lock, M.J., Grainger, M., and Holder, A.A. (2005). Precise epitope mapping of malaria parasite inhibitory antibodies by TROSY NMR cross-saturation. Biochemistry 44, 518-523.

Mugyenyi, C.K., Elliott, S.R., McCallum, F.J., Anders, R.F., Marsh, K., and Beeson, J.G. (2013). Antibodies to polymorphic invasion- 
inhibitory and non-Inhibitory epitopes of Plasmodium falciparum apical membrane antigen 1 in human malaria. PloS one 8 , e68304.

Ohas, E.A., Adams, J.H., Waitumbi, J.N., Orago, A.S., Barbosa, A., Lanar, D.E., and Stoute, J.A. (2004). Measurement of antibody levels against region II of the erythrocyte-binding antigen 175 of Plasmodium falciparum in an area of malaria holoendemicity in western Kenya. Infection Immunity 72, 735-741.

Okech, B.A., Corran, P.H., Todd, J., JoynsonHicks, A., Uthaipibull, C., Egwang, T.G., Holder, A.A., and Riley, E.M. (2004). Fine specificity of serum antibodies to Plasmodium falciparum merozoite surface protein, PfMSP-1(19), predicts protection from malaria infection and high-density parasitemia. Infection Immunity 72, 1557-1567.

Okenu, D.M., Riley, E.M., Bickle, Q.D., Agomo, P.U., Barbosa, A., Daugherty, J.R., Lanar, D.E., and Conway, D.J. (2000). Analysis of human antibodies to erythrocyte binding antigen 175 of Plasmodium falciparum. Infection Immunity 68, 5559-5566.

Omosun, Y.O., Adoro, S., Anumudu, C.I., Odaibo, A.B., Uthiapibull, C., Holder, A.A., Nwagwu, M., and Nwuba, R.I. (2009). Antibody specificities of children living in a malaria endemic area to inhibitory and blocking epitopes on MSP-1 19 of Plasmodium falciparum. Acta tropica 109, 208-212.

Osier, F.H., Fegan, G., Polley, S.D., Murungi, L., Verra, F., Tetteh, K.K., Lowe, B., Mwangi, T., Bull, P.C., Thomas, A.W., Cavanagh, D.R., McBride, J.S., Lanar, D.E., Mackinnon, M.J., Conway, D.J., and Marsh, K. (2008). Breadth and magnitude of antibody responses to multiple Plasmodium falciparum merozoite antigens are associated with protection from clinical malaria. Infection Immunity 76, 2240-2248.

Ouattara, A., Takala-Harrison, S., Thera, M.A., Coulibaly, D., Niangaly, A., Saye, R., Tolo, Y., Dutta, S., Heppner, D.G., Soisson, L., Diggs, C.L., Vekemans, J., Cohen, J., Blackwelder, W.C., Dube, T., Laurens, M.B., Doumbo, O.K., and Plowe, C.V. (2013). Molecular basis of allele-specific efficacy of a blood-stage malaria vaccine: vaccine development implications. J. Inf. Dis. 207, 511-519.

Patarroyo, M.E., Alba, M.P., Reyes, C., RojasLuna, R., and Patarroyo, M.A. (2016a). The Malaria Parasite's Achilles' Heel: Functionally- relevant Invasion Structures. Current issues in molecular biology 18, 11-20.

Patarroyo, M.E., Arevalo-Pinzon, G., Reyes, C., Moreno-Vranich, A., and Patarroyo, M.A. (2016b). Malaria Parasite Survival Depends on Conserved Binding Peptides' Critical Biological Functions. Current issues in molecular biology 18, 57-78.

Patarroyo, M.E., Bermudez, A., and Alba, M.P. (2012). The high immunogenicity induced by modified sporozoites' malarial peptides depends on their phi (phi) and psi (psi) angles. Biochem. Biophy. Res. Comm. 429, 81-86.

Patarroyo, M.E., Cifuentes, G., Pirajan, C., Moreno-Vranich, A., and Vanegas, M. (2010). Atomic evidence that modification of $\mathrm{H}$-bonds established with amino acids critical for hostcell binding induces sterile immunity against malaria. Biochem. Biophy. Res. Comm. 394, 529-535.

Patarroyo, M.E., and Patarroyo, M.A. (2008). Emerging rules for subunit-based, multiantigenic, multistage chemically synthesized vaccines. Acc Chem Res 41, 377-386. PDB. (2016). Protein Data Bank (PDB). www.rcsb.org

Persson, K.E., Fowkes, F.J., McCallum, F.J., Gicheru, N., Reiling, L., Richards, J.S., Wilson, D.W., Lopaticki, S., Cowman, A.F., Marsh, K., and Beeson, J.G. (2013). Erythrocyte-binding antigens of Plasmodium falciparum are targets of human inhibitory antibodies and function to evade naturally acquired immunity. J Immunol 191, 785-794.

Pihlajamaa, T., Kajander, T., Knuuti, J., Horkka, K., Sharma, A., and Permi, P. (2013). Structure of Plasmodium falciparum TRAP (thrombospondin-related anonymous protein) A domain highlights distinct features in apicomplexan von Willebrand factor $A$ homologues. Biochem. J. 450, 469-476.

Pizarro, J.C., Chitarra, V., Verger, D., Holm, I., Petres, S., Dartevelle, S., Nato, F., Longacre, S., and Bentley, G.A. (2003). Crystal structure of a Fab complex formed with PfMSP1-19, the C-terminal fragment of merozoite surface protein 1 from Plasmodium falciparum: a malaria vaccine candidate. Journal of molecular biology 328, 1091-1103.

Richards, J.S., Stanisic, D.I., Fowkes, F.J., Tavul, L., Dabod, E., Thompson, J.K., Kumar, S., Chitnis, C.E., Narum, D.L., Michon, P., Siba, P.M., Cowman, A.F., Mueller, I., and Beeson, J.G. (2010). Association between naturally acquired antibodies to erythrocyte-binding 
antigens of Plasmodium falciparum and protection from malaria and high-density parasitemia. Clinical infectious diseases : an official publication of the Infectious Diseases Society of America 51, e50-60.

Rodriguez, L.E., Curtidor, H., Urquiza, M., Cifuentes, G., Reyes, C., and Patarroyo, M.E. (2008). Intimate molecular interactions of $P$. falciparum merozoite proteins involved in invasion of red blood cells and their implications for vaccine design. Chem Rev 108, 3656-3705.

Sanders, P.R., Kats, L.M., Drew, D.R., O'Donnell, R.A., O'Neill, M., Maier, A.G., Coppel, R.L., and Crabb, B.S. (2006). A set of glycosylphosphatidyl inositol-anchored membrane proteins of Plasmodium falciparum is refractory to genetic deletion. Infection Immunity 74, 4330-4338.

Takala, S.L., Coulibaly, D., Thera, M.A., Batchelor, A.H., Cummings, M.P., Escalante, A.A., Ouattara, A., Traore, K., Niangaly, A., Djimde, A.A., Doumbo, O.K., and Plowe, C.V. (2009). Extreme polymorphism in a vaccine antigen and risk of clinical malaria: implications for vaccine development. Science translational medicine 1, 2ra5.

Tolia, N.H., Enemark, E.J., Sim, B.K., and Joshua-Tor, L. (2005). Structural basis for the EBA-175 erythrocyte invasion pathway of the malaria parasite Plasmodium falciparum. Cell 122, 183-193.

Tossavainen, H., Pihlajamaa, T., Huttunen, T.K., Raulo, E., Rauvala, H., Permi, P., and Kilpelainen, I. (2006). The layered fold of the TSR domain of P. falciparum TRAP contains a heparin binding site. Protein science : a publication of the Protein Society 15, 1760-1768.
Treeck, M., Struck, N.S., Haase, S., Langer, C., Herrmann, S., Healer, J., Cowman, A.F., and Gilberger, T.W. (2006). A conserved region in the EBL proteins is implicated in microneme targeting of the malaria parasite Plasmodium falciparum. J. Biol. Chem. 281, 31995-32003.

Uthaipibull, C., Aufiero, B., Syed, S.E., Hansen, B., Guevara Patino, J.A., Angov, E., Ling, I.T., Fegeding, K., Morgan, W.D., Ockenhouse, C., Birdsall, B., Feeney, J., Lyon, J.A., and Holder, A.A. (2001). Inhibitory and blocking monoclonal antibody epitopes on merozoite surface protein 1 of the malaria parasite Plasmodium falciparum. Journal of molecular biology 307, 1381-1394.

Ware, L.A., Kain, K.C., Lee Sim, B.K., Haynes, J.D., Baird, J.K., and Lanar, D.E. (1993). Two alleles of the 175-kilodalton Plasmodium falciparum erythrocyte binding antigen. Molecular and biochemical parasitology 60, 105-109.

Weiss, G.E., Gilson, P.R., Taechalertpaisarn, T., Tham, W.H., de Jong, N.W., Harvey, K.L., Fowkes, F.J., Barlow, P.N., Rayner, J.C., Wright, G.J., Cowman, A.F., and Crabb, B.S. (2015). Revealing the sequence and resulting cellular morphology of receptor-ligand interactions during Plasmodium falciparum invasion of erythrocytes. PLoS pathogens 11, e1004670.

WHO. (2015). World Malaria Report 2015. World Healt Organization. www.who.int.

Wright, K.E., Hjerrild, K.A., Bartlett, J., Douglas, A.D., Jin, J., Brown, R.E., Illingworth, J.J., Ashfield, R., Clemmensen, S.B., de Jongh, W.A., Draper, S.J., and Higgins, M.K. (2014). Structure of malaria invasion protein $\mathrm{RH} 5$ with erythrocyte basigin and blocking antibodies. Nature 515, 427-430. 